\title{
Análise Multidimensional dos Custos Logísticos contribuindo à Gestão de uma Empresa de Contabilidade
}

Bacharelado em Ciências Contábeis pelo Centro Universitário Estácio do Ceará

Contadora

Rua 2, 142. Conj Arvoredo. Mondubim. Fortaleza/CE. CEP: 60.752-320

E-mail:danca.dan@gmail.com

Rosângela Venâncio Nunes

Mestrado em Logística e Pesquisa Operacional pela Universidade Federal do Ceará -

UFC

Contadora, Consultora e Professora do Centro Universitário Estácio do Ceará e da

Faculdade Ari de Sá - FAS

Rua Sebastião de Abreu, 177, apto 107, bloco C, Maraponga, Fortaleza/CE. CEP:

$60.710-830$

E-mail: angelnuness@gmail.com

Alexandra Alencar Siebra

Doutorado em andamento em Administração e Controladoria pela Universidade Federal do Ceará - UFC Contadora

Avenida Santos Dumont 3665, 1201 A. Aldeota. Fortaleza/CE. CEP: 60.150-165 E-mail: alesiebra@hotmail.com

Charles Washington Costa de Assis Especialização em andamento em Contabilidade, Auditoria e Gestão Tributária pelo Instituto de Pós-Graduação - IPOG Contador e Consultor na Acopeme Assessoria Contábil e Professor no Centro Universitário Estácio do Ceará Rua Sebastião de abreu, 177, apto 107, bloco C. Maraponga. Fortaleza/CE. CEP:

$60.710-830$

E-mail:charles-cont@hotmail.com

Nayana de Almeida Adriano

Doutorado em andamento em Administração e Controladoria pela Universidade Federal do Ceará - UFC Rua Gustavo Sampaio, 1413, apto. 1701. São Gerardo. Fortaleza/CE. CEP: 
Análise Multidimensional dos Custos Logísticos contribuindo à Gestão de uma Empresa de Contabilidade

Danielle Santos Oliveira, Rosângela Venâncio Nunes, Alexandra Alencar Siebra, Charles Washington Costa de Assis, Nayana de Almeida Adriano, Rita de Cassia Fonseca

E-mail: nayanaadriano@hotmail.com

Rita de Cassia Fonseca

Doutorado em andamento em Tecnologia e Sociedade pela Universidade tecnológica

Federal do Paraná - UTFPR

Professora da Universidade Estadual do Centro-Oeste - UNICENTRO Rua Tiradentes 1631. Bairro Centro. Guarapuava/PR. CEP: 85.010-30

E-mail: ritadecfonseca@gmail.com

\section{RESUMO}

O objetivo deste estudo é verificar como a análise multidimensional dos custos logísticos pode contribuir à gestão de uma empresa prestadora de serviços contábeis. Para mostrar a relevância da análise multidimensional dos custos logísticos, como ferramenta para auxiliar o gestor na tomada de decisão, foi realizada uma pesquisa bibliográfica e o estudo de caso em uma empresa de contabilidade, durante o mês de Maio/2018, em que foram coletados dados por meio de entrevistas realizados junto ao sócio da empresa. As análises foram baseadas na Lucratividade Direta por Cliente (LDC) e Lucratividade Direta por Serviços (LDS). Os resultados encontrados são provenientes da análise da LDC e da LDS, comprovando que a análise multidimensional dos custos logísticos é uma ferramenta relevante para auxiliar o empresário desse segmento a tomar decisões que colaborem com o aumento da lucratividade da empresa, através do conhecimento de informações até então não conhecidas pelo gestor.

Palavras-chave: Análise Multidimensional. Custos Logísticos. Serviços Contábeis.

\section{Multidimensional Analysis of Logistic Costs Contributed to the Management of an Accounting Company}

\section{ABSTRACT}

The aim of this study is to verify how a multidimensional analysis of logistics costs can contribute to the management of a company that provides accounting services. In order to show the relevance of the multidimensional analysis of logistical costs, as a tool to assist the manager in decision making, a bibliographic research and a case study were carried out in an accounting firm, during the month of May / 2018, in which data was collected through interviews with the company's partner. The statistics were used in Direct Profitability by the Client (LDC) and Direct Profitability by the Services (LDS). The results found are obtained by analyzing the LDC and the LDS, proven by a multidimensional analysis of logistics costs, a relevant tool to assist or manage these 
Análise Multidimensional dos Custos Logísticos contribuindo à Gestão de uma Empresa de Contabilidade

Danielle Santos Oliveira, Rosângela Venâncio Nunes, Alexandra Alencar Siebra, Charles Washington Costa de Assis, Nayana de Almeida Adriano, Rita de Cassia Fonseca

segments to make decisions that collaborate with increasing the company's profitability, with the knowledge of information until then not specified by the manager.

Key words: Multidimensional Analysis. Logistic costs. Financial Services.

\section{Análisis Multidimensional de los Costos de Logística a Atribuidos a la Gestión de uma Empresa Contable}

\section{RESUMEN}

El propósito de este estudio es verificar cómo el análisis multidimensional de los costos de logística pueden contribuir a la gestión de una empresa que ofrece servicios de contabilidad, con el fin de mostrar la relevancia del análisis multidimensional de los costos de Logística, que sirve como una herramienta para ayudar a la gerencia a tomar decisiones, se realizó una investigación bibliográfica así como un estudio de caso en una empresa de contabilidad durante el mes de mayo del 2018, en el que se recopilaron datos a través de entrevistas con el dueño de la empresa. Los análisis se basaron en la rentabilidad directa por cliente (LDC) y la rentabilidad directa de los servicios (LDS). Los resultados obtenidos provienen del análisis de LDC y LDS, que muestran como el análisis multidimensional de los costos de logística es una herramienta relevante para ayudar al emprendedor de este segmento a tomar decisiones que ayuden con el aumento de la rentabilidad de la empresa, a través del conocimiento de la información que hasta el momento no era conocida por los encargados de la empresa.

Palabras clave: Análisis multidimensional. Costos de logística. Servicios de contabilidad.

\section{INTRODUÇÃO}

As empresas, cada vez mais preocupadas com a concorrência e incertezas produzidas pela globalização, interagem entre si como forma de assegurar sua continuidade. Essa interação resultou em novas estratégias para suas sobrevivências: aliança com fornecedores, fidelização de clientes e, principalmente, o controle dos custos e processos. 
Análise Multidimensional dos Custos Logísticos contribuindo à Gestão de uma Empresa de Contabilidade

Danielle Santos Oliveira, Rosângela Venâncio Nunes, Alexandra Alencar Siebra, Charles Washington Costa de Assis, Nayana de Almeida Adriano, Rita de Cassia Fonseca

A prestação de serviços não fica à exceção desse contexto econômico de concorrência e globalização, tampouco, foge à regra da importância de controlar seus custos.

De acordo com Faria e Costa (2005), o sistema de informação contábil, em especial a gestão de custos, é relevante para tomada de decisão de uma empresa, principalmente no cenário econômico atual.

Os serviços contábeis, estando englobados nessa dinâmica da economia, não estão imunes a essas mudanças. Todas as mudanças e inovações no cenário econômico e cientifico afetaram a forma de execução nas prestações de serviços de contabilidade. Os profissionais desse ramo precisaram se requalificar e mudar a dinâmica na gestão para atender ao mercado que se encontra mais exigente, atendendo à necessidade dos clientes e sempre buscando proporcionar serviços diferenciados em relação aos seus concorrentes.

A logística, numa empresa prestadora de serviços contábeis, terá como objetivo produzir serviços de qualidade, de acordo com a necessidade e pedido do cliente, atendendo-os ao menor tempo possível e a custo mínimo (Faria \& Costa, 2005).

Diante desse contexto de evolução cientifica na contabilidade e de globalização, é essencial que as empresas prestadoras de serviços contábeis acompanhem e analisem as informações produzidas pelo sistema de custos, pois é a partir dessas informações que poderá melhorar a qualidade, pontualidade e eficiência dos serviços prestados.

Dessa forma, os relatórios de rentabilidade são úteis para identificar produtos, clientes, canais de distribuição e regiões que não sejam lucrativos ou não atendam aos objetivos financeiros da empresa (Faria \& Costa, 2005). Muitas organizações focam em analisar os custos e resultados relacionados apenas aos produtos ou serviços ofertados. Os custos dessas atividades devem ser considerados pois são importantes e significativos dentro das empresas, representando, em alguns casos, mais de $10 \%$ do faturamento. Muitas vezes, estes custos não são passíveis de mensuração individual por meio de seus componentes devido às diversas combinações dos eventos geradores 
Análise Multidimensional dos Custos Logísticos contribuindo à Gestão de uma Empresa de Contabilidade

Danielle Santos Oliveira, Rosângela Venâncio Nunes, Alexandra Alencar Siebra, Charles Washington Costa de Assis, Nayana de Almeida Adriano, Rita de Cassia Fonseca

(Engblom, Solakivi, Töyli, \& Ojala, 2012). No entanto, para otimização do resultado econômico, deve ser identificado os custos logísticos relacionados às operações e analisado diversos objetos. A análise multidimensional trata de relacionar esses objetos à rentabilidade da organização.

Os objetos combinados na análise multidimensional podem ser: produtos, regiões, clientes, canal de distribuição, entre outros. $\mathrm{Na}$ análise multidimensional, as ferramentas para combinar seus diversos objetos e ligá-los à rentabilidade da empresa podem ser expostas através da rentabilidade por produto, rentabilidade por cliente, nível de serviço ao cliente, análise de custo logístico por região, canal de distribuição e dimensão do pedido do cliente.

É importante que esforços sejam direcionados para que os ativos financeiros e humanos aplicados nesses processos sejam mínimos, e que as despesas operacionais sejam mantidas no nível mais baixo possível (Bowersox, Closs, Cooper, \& Bowersox, 2013).

Em empresas prestadoras de serviços, inclusive os de serviços contábeis, o enfoque da análise multidimensional será o nível de serviço, pois os seus serviços só irão criar valor para os seus clientes quando forem entregues no momento certo, ao menor custo possível.

Nesse contexto, a questão que se propõe este artigo é: quais são as contribuições da análise multidimensional de custos logísticos quando aplicada no contexto de uma empresa prestadora de serviços contábeis?

Dessa forma, o objetivo geral desse trabalho é verificar como a análise multidimensional dos custos logísticos pode contribuir para a gestão de uma empresa prestadora de serviços contábeis.

Assim, a justificativa deste trabalho se dá pela importância de conhecer e gerenciar os custos logísticos, identificando-os através da análise multidimensional quais são os clientes mais rentáveis para a empresa contábil, quais são serviços que mais geram custos, se é satisfatório manter um contrato ou em qual região isto poderia ser mais rentável, se o nível de serviços ao cliente está satisfatório, etc. Gerenciar os 
Análise Multidimensional dos Custos Logísticos contribuindo à Gestão de uma Empresa de Contabilidade

Danielle Santos Oliveira, Rosângela Venâncio Nunes, Alexandra Alencar Siebra, Charles Washington Costa de Assis, Nayana de Almeida Adriano, Rita de Cassia Fonseca

custos logísticos é de fundamental para esse processo decisório, para que as empresas de serviços contábeis possam conquistar tanto vantagem competitiva em custo quanto em produtividade.

\section{REFERENCIAL TEÓRICO}

\subsection{A Logística e a sua relação com Nível de serviços e Custos Logísticos}

Faria e Costa (2005) definem o objetivo da logística como o de prover ao cliente os níveis de serviços por ele requeridos, com a entrega do produto certo, no lugar certo, no momento certo, nas condições certas e pelo custo certo. Para Ballou (2015) a logística é definida como parte de um processo da cadeia de suprimentos, onde o planejamento, a implantação e o controle, aparecem com o objetivo de trazer eficiência e eficácia na movimentação das operações.

Assim, a gestão logística é relevante para empresa pois é um recurso estratégico na obtenção e sustentação de vantagens competitivas, tanto pela possibilidade de oferecer o melhor nível de serviços ao cliente possível, quanto pela redução dos custos logísticos e melhoria na rentabilidade (Faria \& Costa, 2010). A logística irá fazer a ligação entre o mercado e o operacional da empresa. Seja por razões de rentabilidade ou competitividade, não há como a empresa desconhecer seus custos logísticos, pois sua ação passa por toda a companhia. Conforme Bokor (2010) para auxiliar na tomada de decisão, os gestores devem deter entendimento referente à correta mensuração, além de quais as causa e efeitos dos custos logísticos.

No caso de uma empresa que seja essencialmente prestadora de serviços, a logística ocorrerá mais nos processos internos, uma vez que a mesma não necessita comprar ou vender produtos palpáveis. No entanto, uma empresa de contabilidade, visando manter sua competitividade e observando seus custos, deverá conhecer o seu nível de serviço e custos a ele relacionados.

De acordo com Lima (2000), um dos principais desafios da logística moderna é conseguir a relação entre custo e nível de serviços (trade-off). 
Análise Multidimensional dos Custos Logísticos contribuindo à Gestão de uma Empresa de Contabilidade

Danielle Santos Oliveira, Rosângela Venâncio Nunes, Alexandra Alencar Siebra, Charles Washington Costa de Assis, Nayana de Almeida Adriano, Rita de Cassia Fonseca

Christopher (2011) define a função do nível de serviço ao cliente como sendo utilidade de tempo e de lugar na transferência de mercadorias e serviços entre o comprador e vendedor.

Os serviços contábeis oferecidos para os clientes deverão cumprir os prazos estabelecidos pelos órgãos governamentais, pelos acionistas, pelos credores de seus clientes e etc.

Os serviços somente se tornarão valorosos para o cliente, no momento que ele receber as informações contábeis que atenda suas necessidades. Para que seja possível oferecer um serviço de qualidade é necessário estar capacitado para atender as expectativas dos clientes (Fleury, Wanke, \& Figueiredo, 2000). Dessa forma, os profissionais de contabilidade deverão estar atualizados às normas internacionais e mudança no cenário científico da contabilidade, a fim de atender a demanda dos clientes que vem se tornado mais exigente com toda a concorrência advinda com a globalização.

Para atingir os objetivos dos serviços aos clientes, a logística irá coordenar e implantar sistemas para garantir que seus objetivos sejam cumpridos (Christopher, 1997). Assim surge a logística integrada, que irá trabalhar para oferecer o melhor nível de serviços, agregando valor ao produto/serviços, mas ao menor custo possível.

No entanto, para atingir os objetivos do serviço ao cliente é necessário poder identificar seus custos e mensurá-los afim de que se trabalhe a logística integrada a partir de que a análise dos custos logísticos surge paralelamente à evolução do conceito de logística integrada e ao aumento da exigência do nível de serviço logístico (Pavani Junior \& Scucuglia, 2011).

A visibilidade dos custos logísticos irá ajudar a determinar e a demonstrar os custos existentes na empresa prestadora de serviços contábeis.

\subsubsection{Visibilidade dos Custos Logísticos}

O grande dilema para dar visibilidade aos custos logísticos totais é que os custos gerados nos processos logísticos encontram-se embutidos em diversas rubricas das 
Análise Multidimensional dos Custos Logísticos contribuindo à Gestão de uma Empresa de Contabilidade

Danielle Santos Oliveira, Rosângela Venâncio Nunes, Alexandra Alencar Siebra, Charles Washington Costa de Assis, Nayana de Almeida Adriano, Rita de Cassia Fonseca

demonstrações contábeis, sendo esta uma das grandes dificuldades para identificá-los: o modo pelo qual são classificados e registrados contabilmente pelas empresas. Alguns elementos dos custos logísticos da empresa aparecem na Demonstração de Resultados, outros no Balanço Patrimonial e outros nem são contemplados nessas demonstrações (Faria \& Costa, 2005). Neste sentido, algumas práticas de gestão de custos podem ser utilizadas para controlar e gerenciar os custos logísticos, tais como: custeio baseado em atividades, rentabilidade por produto entre outros (Fleury, 2000). Esse autor complementa que a adoção de práticas de gestão de custos logísticos alinha-se e vem ao encontro do uso de novas tecnologias como mecanismo de dirimir a complexidade dos negócios.

Assim, a contabilidade financeira não é suficiente ou adequada para se extrair informações quanto à tomada de decisão referente aos custos logísticos, pois o seu foco está direcionado apenas aos resultados econômicos.

A importância de se ter a visibilidade dos custos logísticos é válida para que os gestores possam tomar suas decisões de forma mais segura, conhecendo os custos e receitas que serão modificados caso haja alguma alteração no sistema logístico (Faria \& Costa, 2005).

Como os custos logísticos não estão visíveis na contabilidade tradicional, a tomada de decisão quanto à logística da empresa e a gestão desses custos, ficam comprometidas e dificultosas.

Desse modo, a implantação do sistema de custeio $A B C$, demonstrando com precisão os custos ligados a vários objetos, seria capaz de demonstrar relatórios para análise econômica e financeira, mais fidedignas à rentabilidade da empresa.

Uma dessas análises possíveis para a avaliação de desempenho, também relacionado à rentabilidade da empresa a vários objetos, chama-se Análise Multidimensional dos Custos Logísticos. 
Análise Multidimensional dos Custos Logísticos contribuindo à Gestão de uma Empresa de Contabilidade

Danielle Santos Oliveira, Rosângela Venâncio Nunes, Alexandra Alencar Siebra, Charles Washington Costa de Assis, Nayana de Almeida Adriano, Rita de Cassia Fonseca

\subsection{Análise Multidimensional de Custos Logísticos}

Com o conceito da logística integrada, as empresas devem procurar oferecer o melhor nível de serviço ao cliente possível, ao menor custo. Dessa forma, conhecer os custos logísticos da empresa tornou-se fundamental para a otimização dos resultados econômico e financeiros.

O termo multidimensional está associado a um espaço de mais de três dimensões. A análise multidimensional, conforme Faria e Costa (2005), associa os custos logísticos aos seus diversos objetos (fornecedor, cliente, produto, regiões ou canais de distribuição) até chegar ao nível da rentabilidade por cliente, produto ou fornecedor. A análise de rentabilidade pode ser considerada multidimensional, pois pode ser realizada para vários objetos.

Além da aplicação dessa metodologia, é necessário que se tenha o comparativo da receita para os mesmos produtos, clientes e regiões e quais são os custos relacionados.

Christopher (1997) comenta: que um dos princípios básicos de custeio logístico é que o sistema deve ser capaz de identificar os custos resultantes do fornecimento de serviços ao cliente. Um segundo princípio é que ele deve possibilitar uma análise separada de custos e receitas, por tipo de cliente e por segmento de mercado ou canal de distribuição.

No entanto, nem sempre os custos logísticos são facilmente alocados ou relacionados ao seu objeto, pois, alguns desses custos podem ser atribuíveis diretamente ao objeto, enquanto outros indiretos requerem uma apropriação, necessitando de uma análise para esse procedimento. Nos tópicos seguintes serão detalhados e expostos às ferramentas utilizadas para a análise multidimensional.

\subsubsection{Lucratividade por Cliente}

Os custos para cada cliente variam consideravelmente. Como todos os clientes são diferentes, compram serviços distintos, requerem mais ou menos da empresa, é certo que a lucratividade será diferente a cada contrato. 
Análise Multidimensional dos Custos Logísticos contribuindo à Gestão de uma Empresa de Contabilidade

Danielle Santos Oliveira, Rosângela Venâncio Nunes, Alexandra Alencar Siebra, Charles Washington Costa de Assis, Nayana de Almeida Adriano, Rita de Cassia Fonseca

De acordo com Christopher (2011), a lucratividade por cliente, normalmente, é calculada pela diferença entre a receita bruta menos os custos das mercadorias vendidas, ficando à parte outros custos que devem ser considerados para se obter uma boa análise da lucratividade por cliente.

A lucratividade por cliente demonstra quais são os clientes que contribuem de forma negativa ou positiva para o crescimento econômico da empresa.

As informações geradas através da análise da lucratividade criam uma base para negociação de novos contratos, estratégias para vendas e para o marketing. Além de dar suporte para a gestão dos custos por clientes, controlando aqueles que mais custam para a empresa ou aqueles que não geram nenhum resultado positivo.

A matriz de lucratividade por cliente, evidenciada na Figura 1, apresenta informações para orientar o posicionamento estratégico.

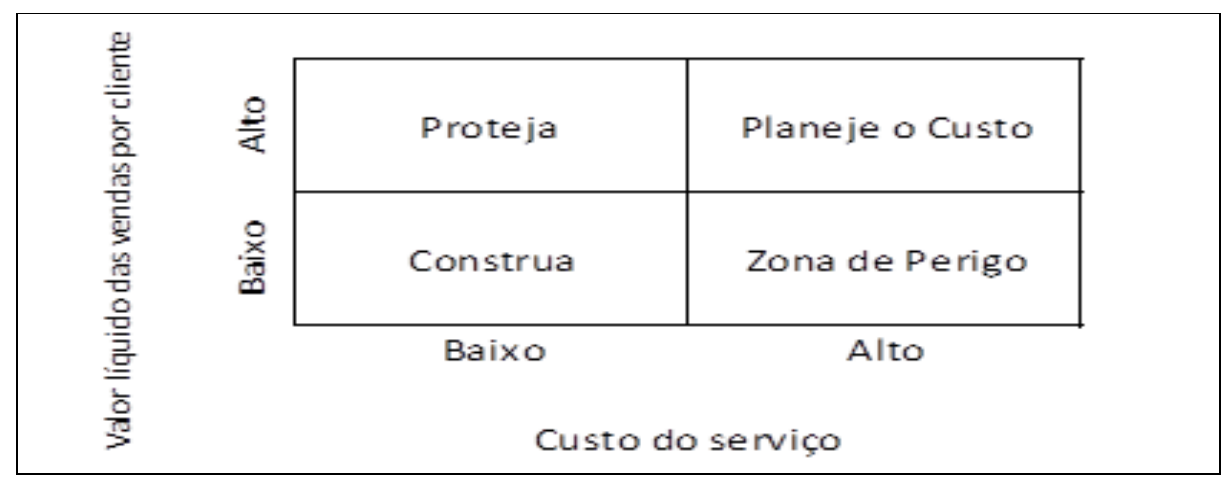

Figura 1. Matriz de Lucratividade por Cliente

Fonte: Christopher (2011, p. 92)

Conforme Christopher (2011), os clientes no quadrante de construa são clientes com a contribuição liquida baixa, devido aos custos e vendas baixas. Proteja são os clientes com melhor retorno para empresa, pois seu valor de liquido são alto para um baixo custo de serviços prestados. Planeje o custo são clientes com nível de retorno alto, mas com custos de serviços também elevados. Esses elevados custos devem ser trabalhados a fim de serem reduzidos para se obter um índice melhor de rentabilidade. Os clientes situados na Zona de perigo possuem uma baixa rentabilidade, com custo de 
Análise Multidimensional dos Custos Logísticos contribuindo à Gestão de uma Empresa de Contabilidade

Danielle Santos Oliveira, Rosângela Venâncio Nunes, Alexandra Alencar Siebra, Charles Washington Costa de Assis, Nayana de Almeida Adriano, Rita de Cassia Fonseca

serviço muito alto. A empresa deve fazer uma análise dos clientes nessa situação, para que se verifique o objetivo, dentro de uma estratégia, em manter esse cliente com a empresa. Assim, as organizações devem procurar analisar sempre a lucratividade por cliente, pois são estes que geram riqueza para a companhia.

Além da lucratividade por cliente, a organização deve ter conhecimento de quais são os seus produtos que contribuem positivamente para a empresa e quais são os que geram prejuízos. A lucratividade direta por produtos (LDP), descrita a seguir apresentar a importância dessa análise.

\subsubsection{Lucratividade Direta por Produto (LDP)}

Semelhante à Lucratividade por Cliente, a Lucratividade Direta por Produto irá buscar alocar os custos específicos ao produto desde a compra junto ao fornecedor até a entrega ao cliente.

A Rentabilidade Direta por Produto (DPP) é uma ferramenta que preconiza identificar os gastos incorridos por produto (SKU) nos diversos canais de distribuição, regiões ou clientes, aperfeiçoando a mensuração da rentabilidade no objeto produto, considerando que seus custos são afetados diretamente por uma decisão específica e que não devem ser utilizados critérios arbitrários. (Faria \& Costa, 2005)

Deste modo, entender e conhecer a LDP para o fornecedor é essencial, uma vez que todos os custos incorridos, à medida que o produto se desloca em seu sistema logístico, influenciarão a sua capacidade de operar, além de irá contribuir com a estratégia de serviços (Christopher, 2011).

Tratando a LDP análoga a Lucratividade Direta por Serviços, muitos dos custos relacionados não serão considerados na análise, uma vez que na prestação de serviços não há armazenagem e transporte. Basicamente na LDS será atribuída a venda de serviços custo de mão-de-obra, uma vez que o produto ofertado na prestação de serviços é intangível, não é palpável, sendo o seu principal custo o intelecto dos funcionários empregados a desenvolver tais serviços. 
Análise Multidimensional dos Custos Logísticos contribuindo à Gestão de uma Empresa de Contabilidade

Danielle Santos Oliveira, Rosângela Venâncio Nunes, Alexandra Alencar Siebra, Charles Washington Costa de Assis, Nayana de Almeida Adriano, Rita de Cassia Fonseca

De acordo com Corrêa e Caon (2002), nas organizações prestadoras de serviços, a lucratividade somente será obtida quando os clientes estiverem satisfeitos. Para tornar o cliente satisfeito, é necessário que os serviços prestados, quando entregues, gerem valor, sendo esse custo capaz de superar as expectativas do tomador de serviço. Na criação desse valor, um recurso essencial seria o recurso humano, que para criar valor em níveis requerido pelo cliente, deveria ter níveis de satisfação (e, portanto retenção) suficientemente altos (Corrêa \& Caon, 2002). Os autores completam afirmando que possuir apenas um bom recurso humano não seja suficiente, é necessário possuir outros recursos como: sistemas, tecnologia, métodos e outros.

$\mathrm{Na}$ gestão de custo da prestação de serviços contábeis apresentada, todos os recursos descritos por Corrêa e Caon (2002) são necessários para a boa qualidade do serviço e satisfação do cliente.

\subsection{Prestação de Serviços Contábeis}

Conforme Fabri e Figueiredo (2000), um bom negócio para uma empresa de contabilidade é prover informações, sendo seu produto relacionado a três áreas de serviços, que são de cunho fiscal, trabalhista e contábil, como também a consultoria e assessoria quando requisitados.

$\mathrm{Na}$ compreensão de Barros (2005), os serviços contábeis consistem na simplificação e clareza dos relatórios e que a sua primordial função contábil é fornecer informações seguras, em tempo hábil, ao processo de gerenciamento das organizações.

Segundo Rodrigues e Lemos (2009), as organizações contábeis atuam como prestador de serviços para outras empresas ou organizações, na sua maioria representada por empresas de pequeno e médio porte.

No entanto, de acordo com Fabri e Figueiredo (2000), um dos principais problemas encontrados pelas empresas de contabilidade é a falta de habilidade gerencial, com pouca importância dada ao gerenciamento dos custos, que algumas ocasiões não são evidenciadas por sua própria pratica contábil. 
Análise Multidimensional dos Custos Logísticos contribuindo à Gestão de uma Empresa de Contabilidade

Danielle Santos Oliveira, Rosângela Venâncio Nunes, Alexandra Alencar Siebra, Charles Washington Costa de Assis, Nayana de Almeida Adriano, Rita de Cassia Fonseca

Partindo do conceito de custo logístico apresentado por Faria e Costa (2005), como sendo aqueles que incorrem ao longo de todo o processo da empresa, partindo dos fornecedores até a entrega do serviço ao cliente, combinado aos custos a serem considerados na apuração da LDS e LDC sugerida por Christopher (2011) em que somente serão considerados os custos logísticos aqueles diretamente atribuíveis ao cliente ou contrato, conclui-se que os custos atribuíveis em uma empresa prestadora de serviços contábeis são: mão-de-obra e licença de software.

Os custos como energia, aluguel, material de escritório e outros não serão considerados como custos logísticos na apuração da LDS e LDC em uma empresa prestadora de serviços contábeis, devido aos custos indiretos não são alocados a não ser que sejam totalmente relativos àquele cliente (Faria \& Costa, 2010).

Para a análise multidimensional dos custos logísticos de uma empresa de serviços contábeis, a metodologia irá expor como essa análise será apurada.

\section{METODOLOGIA}

O presente artigo, quanto à metodologia utilizada, empregou do ponto de vista dos procedimentos técnicos a pesquisa bibliográfica e o estudo de caso.

O estudo de caso foi realizado em uma empresa de contabilidade, que não teve o nome citado no sentido de preservar o sigilo de sua identidade, solicitado pela empresa. A pesquisa foi desenvolvida durante o mês de maio de 2018 , período em que foram coletados dados e realizada entrevista junto ao sócio da empresa. Houve o fornecimento de relatórios tais como: relatório de receitas e despesas, controle de recebimento de clientes e demonstrações contábeis. O estudo teve por base dados reais fornecidos pela empresa, que se referem ao período de dezembro de 2017.

Os dados coletados foram mapeados em planilhas, sendo transformados em tabelas e gráficos para melhor visualização da lucratividade por serviço e por cliente.

Do ponto de vista da forma de abordagem do problema, a pesquisa foi qualitativa. 
Análise Multidimensional dos Custos Logísticos contribuindo à Gestão de uma Empresa de Contabilidade

Danielle Santos Oliveira, Rosângela Venâncio Nunes, Alexandra Alencar Siebra, Charles Washington Costa de Assis, Nayana de Almeida Adriano, Rita de Cassia Fonseca

A metodologia utilizada para essa pesquisa, quanto ao critério do objetivo do estudo, foi exploratória e descritiva. De acordo com Silva e Menezes (2001), a pesquisa descritiva teve como principal objetivo descrever características de uma determinada população, estabelecendo ligações entre as variáveis. A pesquisa também será exploratória, pois pretende encontrar elementos necessários que lhe permitam, em contato com determinada população, obter os resultados que deseja ou servir para levantar possíveis problemas de pesquisa (Silva \& Menezes, 2001).

O procedimento para coleta de dados é de natureza primária, pois se trata de dados extraídos da realidade, pelo trabalho do próprio pesquisador (Prodanov \& Freitas, 2013). Assim, esta pesquisa realiza-se com a coleta de dados relativa ao mês de dezembro de 2017, fornecida pelo sócio da empresa prestadora de serviços contábeis, sobre os custos logísticos existentes nessa atividade e como é a gestão desses custos.

Para análise dos dados, foi realizada uma análise multidimensional dos custos logísticos, utilizando a Lucratividade Direta por Cliente e por Produto.

Por meio das análises de lucratividade, foi observada, de uma forma mais minuciosa, como a análise multidimensional de custos logísticos pode dar suporte para a tomada de decisão.

\section{ESTUDO DE CASO}

\subsection{Estrutura de custos da empresa}

No setor de prestação de serviços contábeis, os custos diretamente atribuíveis aos clientes ou produtos resumem-se à mão-de-obra e licença de software. A estrutura de custos e despesas da entidade estudada é dividida entre quatro setores: pessoal, fiscal, contábil e administrativo.

As atividades desenvolvidas em cada setor resumem-se a: 
Análise Multidimensional dos Custos Logísticos contribuindo à Gestão de uma Empresa de Contabilidade

Danielle Santos Oliveira, Rosângela Venâncio Nunes, Alexandra Alencar Siebra, Charles Washington Costa de Assis, Nayana de Almeida Adriano, Rita de Cassia Fonseca

Pessoal: admissão e demissão de funcionários; elaboração e cálculo da folha de pagamento, férias, $13^{\circ}$ salário e rescisão; cálculo de encargos sociais (FGTS e INSS) e envio de trabalhistas obrigações (GFIP, CAGED, RAIS e DIRF);

Fiscal: lançamento de notas fiscais de entrada e saída; apuração dos impostos federais, estaduais e municipal; envio de obrigações fiscais (SPED, DIEF, DCTF, GISS, DEFIS e DIPJ);

Contábil: registro de lançamentos contábeis; conciliação financeira e patrimonial; elaboração de demonstrações contábeis (Balanços, DRE, DFC e DMPL).

Administrativo: compras; faturista; contas a receber; cobrança, além de enviar e recepcionar documentos.

Os custos dos serviços prestados são diferentes para cada tipo de prestação de serviço, levando em consideração o porte do cliente, faturamento e forma de tributação.

Dos 60 clientes ativos da empresa analisada, dois tem os serviços de contabilidade contratados para serem prestados em suas dependências. Esses clientes, que possuem os serviços contábeis desenvolvidos em suas dependências, são denominados neste artigo de Cliente $S$ e Cliente I. Para esses clientes, fica visível a locação dos custos logísticos atribuíveis a esse cliente. Os Clientes S e I são os que mais contribuem, em termos de faturamento, para a empresa, representam $33,12 \%$ da receita total da empresa. Os demais clientes têm seus serviços executados na própria empresa.

Dessa forma, alocar os custos diretos para cada cliente torna-se uma atividade mais difícil e suscetível a cometer um rateio arbitrário para esses custos. Diante dessa situação, para a elaboração da lucratividade, foi considerado o sistema de alocação dos custos com base nas atividades.

Com isso, a população deste artigo será constituída pelos 60 clientes da empresa de contabilidade e terá uma amostra de seis clientes. Para a LDC e LDS foram escolhidos os dois clientes com custos diretamente atribuíveis e outros quatro clientes que terão seus custos alocados com base nas atividades. Amostra, segundo Marconi e 
Análise Multidimensional dos Custos Logísticos contribuindo à Gestão de uma Empresa de Contabilidade

Danielle Santos Oliveira, Rosângela Venâncio Nunes, Alexandra Alencar Siebra, Charles Washington Costa de Assis, Nayana de Almeida Adriano, Rita de Cassia Fonseca

Lakatos (2003) é uma parcela convenientemente selecionada do universo (população), é um subconjunto do universo. Para esta pesquisa foram escolhidos os clientes utilizando o critério de faturamento, que juntos representam $45,30 \%$ do faturamento total da empresa.

O porte e forma de tributação da amostra são representa na Tabela 1.

Tabela 1

Tributação e Porte das empresas da amostra

\begin{tabular}{lcc}
\hline \multicolumn{1}{c}{ Clientes } & Tributação & Porte \\
\hline Cliente I & Sem fins lucrativos & Médio \\
Cliente S & Lucro Real & Médio \\
Cliente A & Simples Nacional & Pequeno \\
Cliente B & Lucro Presumido & Pequeno \\
Cliente C & Simples Nacional & Pequeno \\
Cliente D & Simples Nacional & Pequeno \\
\hline
\end{tabular}

Nota. Fonte: Elaborado pelos autores baseado nos dados fornecidos pela empresa.

Para fins de determinação da LDC e LDS, será considerada como custos logísticos, a mão-de-obra e licença de software. O critério para determinação dos custos logísticos não atribuíveis diretamente ao cliente ocorrerá de acordo com os registros/lançamentos realizados no sistema contábil.

Quanto aos serviços oferecidos pela empresa e considerando que as receitas provenientes de auditoria e consultoria não são frequentes, para fins desse artigo, será utilizado para a análise da LDS apenas os serviços de Assessoria Contábil (nesses serviços são considerados também a assessoria fiscal e pessoal) e Constituição e Registro de Empresas.

A Tabela 2 identifica os custos variáveis unitários por lançamento/registro, atribuídos aos clientes da empresa contábil de acordo com a utilização do sistema para os serviços de assessoria contábil. 
Análise Multidimensional dos Custos Logísticos contribuindo à Gestão de uma Empresa de Contabilidade Danielle Santos Oliveira, Rosângela Venâncio Nunes, Alexandra Alencar Siebra, Charles Washington Costa de Assis, Nayana de Almeida Adriano, Rita de Cassia Fonseca

Tabela 2

Custos por Serviços

\begin{tabular}{ccr}
\hline Custos por Serviço \\
\hline Custos & Assessoria Contábil & $\begin{array}{c}\text { Abertura e Registro } \\
\text { de Empresas }\end{array}$ \\
\hline Mão-de-obra & 1,93 & 362,00 \\
Software & 0,14 & 0,00 \\
Taxas & & 150,00 \\
Deslocamentos & & 50,00 \\
\hline Total & $\mathbf{2 , 0 7}$ & $\mathbf{5 6 2 , 0 0}$ \\
\hline
\end{tabular}

Nota. Fonte: Elaborado pelos autores baseado nos dados fornecidos pela empresa.

Quanto aos serviços de constituição e registro de empresas, os custos são estimados pelo sócio da mesma. Para maior comodidade do cliente, a empresa já inclui, no custo dos seus serviços, as despesas com cartório, taxas para registro, além das despesas como deslocamento para os órgãos de registro.

Baseado nos custos por serviços, a seguir, será demonstrada a análise multidimensional dos custos logísticos da empresa de uma empresa do ramo contábil.

\subsection{Análise Multidimensional}

A análise multidimensional dos custos logísticos possibilita a análise dos custos associados a vários objetos. O objeto abordado neste trabalho será limitado ao cliente e serviço (produto). Para a análise, foram utilizadas as ferramentas indicadas por Faria e Costa (2005): Lucratividade Direta por Cliente (LDC ou DPP - Direct Profitability Products) e Lucratividade Direta por Produto, sendo neste trabalho adaptada para Lucratividade Direta por Serviços.

Para a empresa encontrar sua Lucratividade Direta por Cliente, deve ter conhecimento dos custos a ele diretamente atribuíveis. Segundo Christopher (2011), para conhecer os custos inerentes ao cliente, deve ser feito o seguinte questionamento: quais seriam os custos evitados e quais as receitas perdidas se eu deixasse de atender esse cliente? 
Análise Multidimensional dos Custos Logísticos contribuindo à Gestão de uma Empresa de Contabilidade

Danielle Santos Oliveira, Rosângela Venâncio Nunes, Alexandra Alencar Siebra, Charles Washington Costa de Assis, Nayana de Almeida Adriano, Rita de Cassia Fonseca

Para realizar a análise da rentabilidade por cliente, foi levada em consideração, como custos logísticos, a mão-de-obra e a licença de software.

Considerando que boa parte da mão-de-obra está concentrada na unidade da empresa, que atende o maior do número de clientes, foi calculado o custo da mão-deobra mensal, incluindo todas as obrigações trabalhistas. Na Tabela 3, é demonstrado o cálculo do Custo Geral com mão-de-obra.

Tabela 3

\section{Custos Geral da Mão-de-obra}

\begin{tabular}{|c|c|c|c|c|c|c|c|c|}
\hline \multicolumn{9}{|c|}{ Custo Geral de Mão-de-obra } \\
\hline Funcionários & Salário & Estagiário & Férias & $\begin{array}{c}13 \\
\text { salário }\end{array}$ & FGTS & INSS & VA & Total \\
\hline Funcionário - Cliente S & $1.634,25$ & & 181,58 & 136,19 & 156,16 & 78,08 & 220,00 & $2.406,26$ \\
\hline $\begin{array}{l}\text { Funcionário - Cliente I } \\
\text { Funcionários - Setor }\end{array}$ & $1.634,25$ & 433,33 & 181,58 & 136,19 & 156,16 & 78,08 & 220,00 & $2.839,60$ \\
\hline $\begin{array}{l}\text { Pessoal } \\
\text { Funcionários - Setor }\end{array}$ & 720,00 & 433,33 & 80,00 & 60,00 & 68,80 & 34,40 & 220,00 & $1.616,53$ \\
\hline $\begin{array}{l}\text { Contábil } \\
\text { Funcionários - Setor }\end{array}$ & $1.660,00$ & $1.217,67$ & 184,44 & 138,33 & 158,62 & 79,31 & 220,00 & $3.658,38$ \\
\hline $\begin{array}{l}\text { Fiscal } \\
\text { Funcionários - }\end{array}$ & 830,00 & - & 92,22 & 69,17 & 79,31 & 39,66 & 220,00 & $1.330,36$ \\
\hline Administrativo & 720,00 & - & 80,00 & 60,00 & 68,80 & 34,40 & 220,00 & $1.183,20$ \\
\hline
\end{tabular}

Nota. Fonte: Elaborado pelos autores baseado nos dados fornecidos pela empresa.

Os funcionários alocados ao Cliente $\mathrm{S}$ e Cliente I têm seus custos atribuídos diretamente ao contrato de prestação de serviços, uma vez que desenvolvem atividades no estabelecimento do cliente que são exclusivos para os mesmos. Quanto aos funcionários que desenvolvem suas atividades na empresa, foram classificados de acordo com o setor de trabalho. Para fins das análises, não será considerado o funcionário-administrativo, uma vez que os seus custos não são vinculados a um cliente especifico, além da falta de critério para alocar seus dispêndios.

Para encontrar o custo da mão-de-obra da empresa contábil com base no total de registro, foi realizada uma auditoria no sistema com o total de registro nos três 
Análise Multidimensional dos Custos Logísticos contribuindo à Gestão de uma Empresa de Contabilidade

Danielle Santos Oliveira, Rosângela Venâncio Nunes, Alexandra Alencar Siebra, Charles Washington Costa de Assis, Nayana de Almeida Adriano, Rita de Cassia Fonseca

setores. Os registros incluem: folha de pagamento, férias, admissões, rescisões, lançamentos contábeis, registro de notas fiscais e etc. O total de registro no mês de Dezembro de 2017 foi de 26.704 registros. O total de registro também serviu como base para apropriação do custo da licença de software.

A Tabela 4 demonstra o custo do sistema por setor, considerando os registros realizados para cada um. Em seguida é apurado o custo da mão-de-obra com base no total de registros.

O valor informado na Tabela 4, referente ao custo de mão-de-obra, foi apurado na Tabela 3. O custo por registro foi encontrado através da divisão do custo de mão-deobra pelo o total de registros de cada setor.

Tabela 4

Custo com utilização do Software e Custo da mão-de-obra com base na utilização do Software

\begin{tabular}{lccc|ccc}
\hline Utilização do Software & & \multicolumn{3}{c}{$\begin{array}{c}\text { Utilização da } \\
\text { Mão-de-Obra }\end{array}$} \\
\hline Setor & $\begin{array}{c}\text { Custo } \\
\text { do } \\
\text { Tegistros }\end{array}$ & $\begin{array}{c}\text { Custo com } \\
\text { Licença } \\
\text { do Software }\end{array}$ & $\begin{array}{c}\text { Sistema } \\
\text { Vlr. } \\
\text { Unitário }\end{array}$ & $\begin{array}{c}\text { Custo com } \\
\text { Mão-de-obra }\end{array}$ & $\begin{array}{c}\text { Valor } \\
\text { por } \\
\text { Registro }\end{array}$ \\
\hline Setor Pessoal & 1041 & 126,63 & 0,1216 & 16.165 .333 & 1,5529 \\
Setor Contábil & 13433 & 99,14 & 0,0074 & 3.6583778 & 0,2723 \\
Setor Fiscal & 12230 & 99,14 & 0,0081 & 1.330 .3556 & 0,1088 \\
\hline Total & $\mathbf{2 6 7 0 4}$ & $\mathbf{3 2 4 , 9 1}$ & $\mathbf{0 , 1 3 7 1}$ & $\mathbf{6 . 6 0 5 . 2 6 6 7}$ & $\mathbf{1 , 9 3 4 0}$ \\
\hline
\end{tabular}

Nota. Fonte: Elaborado pelos autores baseado nos dados fornecidos pela empresa.

Conhecido o valor do custo da mão-de-obra por registro, verificou-se o total de lançamentos/registro realizado para cada cliente, em cada setor, conforme demonstrado na Tabela 5. 
Análise Multidimensional dos Custos Logísticos contribuindo à Gestão de uma Empresa de Contabilidade

Danielle Santos Oliveira, Rosângela Venâncio Nunes, Alexandra Alencar Siebra, Charles Washington Costa de Assis, Nayana de Almeida Adriano, Rita de Cassia Fonseca

Tabela 5

Utilização do software por cliente

\begin{tabular}{lccc}
\hline \multicolumn{4}{c}{ Utilização do Software por cliente } \\
\hline Cliente & Setor Pessoal & Setor Fiscal & Setor Contábil \\
\hline Cliente A & 29 & 668 & 200 \\
Cliente B & 34 & 1017 & 1150 \\
Cliente C & 49 & 2670 & 1149 \\
Cliente D & 10 & 291 & 350 \\
\hline
\end{tabular}

Nota. Fonte: Elaborado pelos autores baseado nos dados fornecidos pela empresa.

Para encontrar custo com mão-de-obra para cada cliente, exceto o Cliente S e Cliente I, foi multiplicado o valor de cada registro pelo seu respectivo custo, todos de acordo com cada setor. Para o Cliente I, toda mão-de-obra foi considerado como custo para o setor contábil, pois os outros setores não fazem parte do contrato de prestação de serviços. O funcionário alocado ao Cliente $S$ desenvolve atividade do setor fiscal e contábil, como fica demonstrado na Tabela 6.

Tabela 6

Custo de mão-de-obra por Cliente

\begin{tabular}{|c|c|c|c|c|}
\hline \multicolumn{5}{|c|}{ Custo de mão-de-obra por Cliente } \\
\hline Cliente & Setor Pessoal & Setor Fiscal & Setor Contábil & $\begin{array}{c}\text { Total do Custo } \\
\text { com } \\
\text { Mão-de-obra }\end{array}$ \\
\hline Cliente S & - & 481,25 & $1.925,01$ & $2.406,26$ \\
\hline Cliente I & - & - & $2.839,60$ & $2.839,60$ \\
\hline Cliente A & 45,03 & 72,66 & 54.47 & 172,17 \\
\hline Cliente B & 52,80 & 110,63 & 313,19 & 476,62 \\
\hline Cliente C & 76,09 & 290,44 & 312,92 & 679,45 \\
\hline Cliente D & 15,53 & 31,65 & 95,32 & 142,50 \\
\hline
\end{tabular}

Nota. Fonte: Elaborado pelos autores baseado nos dados fornecidos pela empresa. 
Análise Multidimensional dos Custos Logísticos contribuindo à Gestão de uma Empresa de Contabilidade

Danielle Santos Oliveira, Rosângela Venâncio Nunes, Alexandra Alencar Siebra, Charles Washington Costa de Assis, Nayana de Almeida Adriano, Rita de Cassia Fonseca

Para o cálculo do custo com software, foi utilizada a mesma metodologia para alocação dos custos com a mão-de-obra. Com base na Tabela 4, o valor unitário do custo com software foi multiplicado pela quantidade de registros efetuados. O cliente $S$ tem sistema próprio e custeado por ele mesmo. Para o Cliente I é pago uma cópia de licença do software. O valor total pago por a cópia da licença é atribuído diretamente ao cliente.

Com os custos calculados e atribuídos a cada cliente, é possível encontrar a lucratividade direta para cada cliente conforme demonstrado na Tabela 7.

Tabela 7

Lucratividade Direta por Cliente

\begin{tabular}{lcccccc}
\hline \multicolumn{7}{c}{ Lucratividade Direta por Cliente } \\
\hline & Cliente S & Cliente I & Cliente A & Cliente B & Cliente C & Cliente D \\
\hline Receitas Bruta & $4.163,84$ & $4.870,00$ & $1.017,00$ & $1.458,15$ & 339,00 & 508,00 \\
Custo com Mão-de-Obra & $2.406,26$ & $2.839,60$ & 172,17 & 476,62 & 679,45 & 142,5 \\
Custo com Software & 0,00 & 204,48 & 10,42 & 20,87 & 36,08 & 6,16 \\
Lucratividade por Cliente & $\mathbf{1 . 7 5 7 , 5 8}$ & $\mathbf{1 . 8 2 5 , 9 2}$ & $\mathbf{8 3 4 , 4 2}$ & $\mathbf{9 6 0 , 6 6}$ & $\mathbf{- 3 7 6 , 5 3}$ & 359,34 \\
\hline
\end{tabular}

Nota. Fonte: Elaborado pelos autores baseado nos dados fornecidos pela empresa.

De acordo com a lucratividade apresentada, constata-se que o Cliente I é o de maior rentabilidade para a empresa. Seu faturamento representa $17,85 \%$ do total da receita de prestação de serviços contábeis. Do total da receita bruta desse cliente, $62,50 \%$ (58,30\% para a mão-de-obra e $4,2 \%$ para o custo com software) foram consumidos pelos custos diretamente atribuídos a esse cliente. Além de apresentar a maior lucratividade, o Cliente I também apresenta o maior percentual de custo atribuído em relação à receita. O Cliente $A$ apresenta a terceira maior lucratividade, no entanto, possui o menor percentual de custo atribuído, representando apenas $17,95 \%$ do total da receita bruta.

O Cliente $\mathrm{C}$, de acordo com a LDC, tem contribuído de forma negativa com a lucratividade da empresa. $O$ total dos custos atribuídos a esse cliente chega a 
Análise Multidimensional dos Custos Logísticos contribuindo à Gestão de uma Empresa de Contabilidade

Danielle Santos Oliveira, Rosângela Venâncio Nunes, Alexandra Alencar Siebra, Charles Washington Costa de Assis, Nayana de Almeida Adriano, Rita de Cassia Fonseca

representar $211 \%$ do total da receita bruta, ou seja, os valores do custo representam duas vezes mais o valor ganho com a receita. $O$ custo da prestação dos serviços contábeis para esse cliente concentra-se na mão-de-obra com o setor contábil.

$\mathrm{Na}$ Lucratividade Direta por Serviços, foram eleitos os dois serviços mais desenvolvidos pela empresa que são os serviços de auditoria e de consultoria, por não serem prestados com frequência e ter uma participação pouco significante em relação à receita bruta da empresa.

A Tabela 8 apresenta a Lucratividade Direta por Serviço. Os serviços de assessoria contábil são precificados com base na forma de tributação do cliente. Após seis meses de contrato, os honorários poderão ser ajustados levando em consideração a receita, volume de emissão de documentos fiscais, quantidade de admissões e demissões, além da movimentação financeira. Verificando a dimensão do trabalho, os honorários podem ser reajustados, conforme previsão contratual.

Tabela 8

Lucratividade Direta por Serviço

\begin{tabular}{lccc}
\hline \multicolumn{4}{c}{ Lucratividade Direta por Serviço } \\
\hline Serviços & Receita Bruta & Custos & Lucratividade \\
\hline Assessoria Contábil - ME - EPP & 678,00 & 414,22 & 263,78 \\
Assessoria Contábil - Lucro Presumido & $1.810,00$ & $1.242,67$ & 567,33 \\
Assessoria Contábil - Lucro Real & $3.620,00$ & $2.071,12$ & $1.548,88$ \\
Abertura e Registro de Empresas & 678,00 & 562,00 & 116,00 \\
\hline
\end{tabular}

Nota. Fonte: Elaborado pelos autores baseado nos dados fornecidos pela empresa.

Para a empresa, os clientes que mais irão contribuir com a rentabilidade da empresa, serão aqueles tributados pelo Lucro Real. No entanto, apesar desses serviços serem os mais rentáveis, os custos logísticos é o mais elevado.

A Tabela 09 trata de agrupar as informações obtidas com a LDS e LDC. 
Análise Multidimensional dos Custos Logísticos contribuindo à Gestão de uma Empresa de

Contabilidade

Danielle Santos Oliveira, Rosângela Venâncio Nunes, Alexandra Alencar Siebra, Charles Washington Costa de Assis, Nayana de Almeida Adriano, Rita de Cassia Fonseca

Tabela 09

Análise da LDS e LDC

\begin{tabular}{|c|c|c|c|c|c|c|c|c|c|c|}
\hline \multicolumn{6}{|c|}{ LDS } & \multicolumn{5}{|c|}{ LDC } \\
\hline Serviços/Clientes & $\begin{array}{l}\text { Assessoria } \\
\text { Contábil } \\
\text { - ME - EPP }\end{array}$ & $\begin{array}{c}\text { Assessoria } \\
\text { Contábil } \\
\text { Lucro } \\
\text { Presumido }\end{array}$ & $\begin{array}{c}\text { Assessoria } \\
\text { Contábil - } \\
\text { Lucro } \\
\text { Real }\end{array}$ & $\begin{array}{c}\text { Abertura } \\
\text { e } \\
\text { Registro } \\
\text { de } \\
\text { Empresas }\end{array}$ & $\begin{array}{c}\text { Cliente } \\
\mathrm{S}\end{array}$ & Cliente I & $\begin{array}{c}\text { Cliente } \\
\text { A }\end{array}$ & $\begin{array}{c}\text { Cliente } \\
\text { B }\end{array}$ & $\begin{array}{c}\text { Cliente } \\
\text { C }\end{array}$ & $\begin{array}{c}\text { Cliente } \\
\text { D }\end{array}$ \\
\hline Receita Bruta & 678,00 & $1.810,00$ & $3.620,00$ & 678,00 & $4.163,84$ & $4.870,00$ & $1.017,00$ & $1.458,15$ & 339,00 & 508,00 \\
\hline Lucratividade & 263,78 & 567,33 & $1.548,00$ & 116,00 & $1.757,58$ & $1.825,92$ & 834,42 & 960,66 & $-376,53$ & 359,34 \\
\hline Margem de Lucro & $38,91 \%$ & $31,34 \%$ & $42,79 \%$ & $17,11 \%$ & $42,21 \%$ & $37,49 \%$ & $82,05 \%$ & $65,88 \%$ & $111,07 \%$ & $70,74 \%$ \\
\hline
\end{tabular}

Nota. Fonte: Elaborado pelos autores baseado nos dados fornecidos pela empresa.

Ao analisar as tipologias de lucratividades (LDS e LDC), observa-se que os valores de contribuição dos clientes, não atendem as expectativas fixadas pela lucratividade do produto. $\mathrm{O}$ fato deve-se a definição dos honorários contábeis abaixo da estimativa para os serviços de menor complexidade, como é o exemplo da situação do Cliente C. A receita bruta estimada para o produto é de $R \$ 678,00$, enquanto o valor contratual desse cliente é $R \$ 339,00$, gerando um déficit na receita de $R \$ 339,00$.

Os serviços de Assessoria Contábil - Lucro Real chega próximo às expectativas de lucratividade encontrada na LDC. O Cliente S, como informado na Tabela 1, tem sua tributação com base no Lucro Real, gerando uma rentabilidade de acordo com a LDC de $42,21 \%$, enquanto que, para esse tipo de cliente na LDS, a expectativa é de $42,23 \%$.

A lucratividade por serviços é impactante ao se observar o Cliente A. Para o perfil desse cliente, a LDS prevê uma lucratividade de $28,48 \%$ para empresas do Simples Nacional, enquanto que a LDC desse cliente apresenta uma margem de lucro de $82 \%$. Essa diferença é decorrente da receita bruta praticada na LDS (R\$ 678,00) entre a $\operatorname{LDC}(\mathrm{R} \$ 1.017,00)$.

Observa-se que $50 \%$ dos clientes analisados estão com o valor da receita bruta acima dos honorários sugeridos na LDS, enquanto que os outros $50 \%$ apresentam situação inversa. 
Análise Multidimensional dos Custos Logísticos contribuindo à Gestão de uma Empresa de Contabilidade

Danielle Santos Oliveira, Rosângela Venâncio Nunes, Alexandra Alencar Siebra, Charles Washington Costa de Assis, Nayana de Almeida Adriano, Rita de Cassia Fonseca

Os clientes que não atingiram a expectativa da receita bruta sugerida na LDS, têm tendência a apresentar uma rentabilidade negativa, uma vez que a receita fixa na LDS é baseada na expectativa de rentabilidade positiva.

Com os resultados obtidos através da LDC e LDS, observa-se que a empresa de serviços contábeis passará a ter uma base para precificação de honorários de acordo com o porte do cliente, além de conhecerem a real lucratividade apresentada por cada cliente. Essas ferramentas servirão de base para tomada de decisão do gestor da empresa, tanto quanto aos honorários a serem reajustados ou custos realocados, quanto aos contratos que apenas contribuem de forma negativa para a lucratividade da empresa.

Após as análises, fica clara a importância da análise multidimensional para a lucratividade da empresa, pois é a partir dessa análise que pode ser relacionado os custos aos seus objetos, como cliente e serviços ofertados e respaldar as decisões gerenciais quanto aos clientes que deverão ser retidos ou aqueles que deverão ser reincididos para garantir uma boa lucratividade para a empresa.

A análise multidimensional dos custos logísticos, utilizando as ferramentas LDS e LDC, contribui para as empresas prestadoras de serviços contábeis na formação de preços, reajustes de honorários e rescisão contratual em função da rentabilidade negativa apresentam para o contrato.

A LDS contribuiu, significativamente, no momento de precificar honorários, pois o conhecimento dos custos vinculados a todas as modalidades de prestação de serviços é fundamental para saber até onde a empresa pode minimizar os honorários estabelecidos, sem comprometer sua margem de lucro. Também serve para otimizar os custos que mais oneram os serviços, utilizando a gestão de custos, a fim de minimizá-los, contribuindo para uma empresa mais competitiva.

A LDC ajudou a identificar que o Cliente $C$ não tem colaborado, positivamente, com a lucratividade da empresa, enquanto que o Cliente I contribuiu com uma grande parcela positiva, para a rentabilidade da empresa. Conhecer os custos vinculados a 
Análise Multidimensional dos Custos Logísticos contribuindo à Gestão de uma Empresa de Contabilidade

Danielle Santos Oliveira, Rosângela Venâncio Nunes, Alexandra Alencar Siebra, Charles Washington Costa de Assis, Nayana de Almeida Adriano, Rita de Cassia Fonseca

cada cliente fundamenta o gestor a tomar decisões quanto aos contratos que devem ser reajustados ou reincididos, a fim de alavancar a lucratividade da empresa.

\section{CONSIDERAÇÕES FINAIS}

A gestão dos custos logísticos, baseada na análise multidimensional, serve como uma ferramenta para auxiliar os gestores na tomada de decisão, pois, ao controlar os custos sob o ponto de vista de vários objetos, a empresa passa a ter um maior conhecimento dos seus custos logísticos, trabalhando na otimização e redução destes custos.

Com a análise multidimensional dos custos logísticos, percebe-se que os valores de receita bruta estimados na LDS, em alguns clientes, estão abaixo dos praticados, gerando uma lucratividade negativa para empresa, conforme demonstrado na LDC. Sem esse conhecimento, muitas vezes, os gestores de empresas de contabilidade fecham contratos sem conhecer a margem de lucro gerada pelo novo cliente ou os custos que serão inerentes a esse cliente a fim de estabelecer o preço dos honorários mais condizentes com sua expectativa de ganho.

Diante disso, fica clara a relevância desta produção em razão de a empresa não utilizar nenhuma informação sobre os custos relativos à prestação de serviços, estipulando seus honorários com base no bom senso e, num mercado que a contabilidade é vista como apenas uma obrigatoriedade a ser cumprido pela empresa e, como conseqüência, dessas visões a melhor empresa contábil seria aquela que o preço cobrado pelo serviço é o mais barato.

A partir desta pesquisa, a empresa poderá realizar um melhor controle dos seus custos e honorários, analisando, periodicamente, quais são os clientes que dão prejuízo ou quais são os seus serviços que precisam ser reajustados, a fim de manter a empresa no mercado competitivo e otimizar sua lucratividade. A pesquisa já demonstrou que para o Cliente $\mathrm{C}$ os honorários deverão ser reajustados ou os custos otimizados para esse cliente gere uma lucratividade positiva para a empresa estudada, 
Análise Multidimensional dos Custos Logísticos contribuindo à Gestão de uma Empresa de Contabilidade

Danielle Santos Oliveira, Rosângela Venâncio Nunes, Alexandra Alencar Siebra, Charles Washington Costa de Assis, Nayana de Almeida Adriano, Rita de Cassia Fonseca

além disso, o Cliente I deve ser trabalhado para que haja a retenção desse cliente já que ele gera mais resultados para a empresa em relação aos outros.

\section{REFERÊNCIAS}

Ballou, R. H. (1993). Logística empresarial: transportes, administração de materiais e distribuição física. Atlas.

Ballou, R. H. (2009). Gerenciamento da Cadeia de Suprimentos-: Logística Empresarial. Bookman Editora.

Barros, V. D. M. (2005). O novo velho enfoque da informação contábil. Revista Contabilidade \& Finanças, 16(38), 102-112.

Bokor, Z. (2010). Cost drivers in transport and logistics. Periodica Polytechnica Transportation Engineering, 38(1), 13-17.

Bowersox, D. J., Closs, D. J., Cooper, M. B., \& Bowersox, J. C. (2013). Gestão logística da cadeia de suprimentos. AMGH Editora.

Christopher, M. (1997). Logística e gerenciamento da cadeia de suprimentos: estratégias para a redução de custos e melhoria dos serviços. Pioneira.

Christopher, M. (1997). Logística e gerenciamento da cadeia de suprimentos: estratégias para a redução de custos e melhoria dos serviços. Pioneira.

Corrêa, H. L., Caon, M., \& Gianesi, I. G. (2002). Gestão de serviços: lucratividade por meio de operações e de satisfação dos clientes. São Paulo: Atlas.

Engblom, J., Solakivi, T., Töyli, J., \& Ojala, L. (2012). Multiple-method analysis of logistics costs. International Journal of Production Economics, 137(1), 29-35.

Faria, A. C. D., \& Costa, M. D. F. G. D. (2005). Gestão de custos logísticos. São Paulo: Atlas, 147-161.

Faria, A. C. D., \& Costa, M. D. F. G. D. (2005). Gestão de custos logísticos. São Paulo: Atlas, 147-161.

Figueiredo, S., \& Fabri, P. E. (2000). Gestão de empresas contábeis. Atlas.

Fleury, P. F., Wanke, P., \& Figueiredo, K. F. (2000). Logística empresarial: a perspectiva brasileira. Editora Atlas SA. 
Análise Multidimensional dos Custos Logísticos contribuindo à Gestão de uma Empresa de Contabilidade

Danielle Santos Oliveira, Rosângela Venâncio Nunes, Alexandra Alencar Siebra, Charles Washington Costa de Assis, Nayana de Almeida Adriano, Rita de Cassia Fonseca

Lakatos, E. M., \& Marconi, M. A. (2003). Fundamentos de metodologia científica. (5a ed.).

Lima, M. P., \& Fleury, P. (1998). Custos logísticos: uma visão gerencial.

Pavani Junior, O., \& Scucuglia, R. (2011). Mapeamento e gestão por processosBPM. São Paulo: M. Books.

Prodanov, C. C., \& de Freitas, E. C. (2013). Metodologia do trabalho científico: métodos e técnicas da pesquisa e do trabalho acadêmico. (2a ed.). Editora Feevale.

Rodrigues, A. T. L., \& de Lemos, I. S. (2009). Ferramentas de gestão para organizações contábeis. ConTexto, 9(16).

Silva, E. L. D., \& Menezes, E. M. (2001). Metodologia da pesquisa e elaboração de dissertação.

Data de Submissão: 13/08/2018

Data de Aceite: 07/05/2020 